\title{
UTILIZAÇÃO DO APLICATIVO PLICKERS NO ENSINO DA MATEMÁTICA
}

\author{
Fabio Henrique Marinho Cabral ${ }^{\star}$ \\ *E-mail: fabiohmc2005@gmail.com \\ Instituto Federal de Educação, Ciência e Tecnologia do Pará, Brasil \\ DOI: 10.15628/rbept.2020.7939
}

Artigo submetido em nov/2018 e aceito em mar/2020

\begin{abstract}
RESUMO
As novas tecnologias educacionais são ótimas ferramentas que auxiliam o processo de ensino aprendizagem. Utilizá-las como recurso na avaliação formativa é uma excelente maneira para o educador verificar se os seus objetivos em relação ao conteúdo didático estão sendo alcançados. Destarte, propomos a análise de um relato de experiência através de um teste avaliativo de matemática utilizando o aplicativo plickers em uma turma de segundo ano do ensino médio com a finalidade de verificar qual a contribuição deste para o ensino-aprendizagem de matemática. Apresentamos todas as etapas necessárias ao planejamento da atividade envolvendo o aplicativo, e distribuímos ao final do teste, um questionário semiestruturado a fim de verificar a percepção dos estudantes sobre o uso desta tecnologia. Após a análise dos dados, verificamos que a utilização do aplicativo possibilita uma rápida intervenção por parte do professor em decorrência do imediato diagnóstico dos assuntos com maior incidência de erros dos alunos, além de uma grande aceitação dos estudantes devido a ludicidade que esta tecnologia possui.
\end{abstract}

Palavras-chave: Tecnologias. Educacionais. Plickers. Avaliação. Ensino.

\section{USING THE PLICKERS APPLICATION IN MATHEMATICS TEACHING}

\begin{abstract}
New educational technologies are great tools that help the teaching-learning process. Using them as a resource in formative assessment is an excellent way for educators to verify that their goals in relation to the didactic content are being met. Thus, we propose the analysis of an experience report through an evaluative math test using the plickers application in a second-year high school class in order to verify its contribution to the teaching and learning of mathematics. We present all the steps necessary to plan the activity involving the application, and distribute a semi-structured questionnaire at the end of the test to verify students' perceptions of the use of this technology. After analyzing the data, we found that the use of the application enables a quick intervention by the teacher due to the immediate diagnosis of the subjects with higher incidence of student errors, as well as a high acceptance of students due to the playfulness that this technology has.
\end{abstract}

Keywords: Technologies. Educational. Plickers. Evaluation. Teaching. 


\section{INTRODUÇÃO}

O método avaliativo a ser empregado na sala de aula é de suma importância e de grande relevância para o processo de ensino e aprendizagem, através dele o docente tem a oportunidade de buscar compreender de que maneira as atividades desenvolvidas em sala de aula estão contribuindo de forma significativa para o desempenho do aluno. Dessa forma, buscar reflexões acerca do processo avaliativo nos leva a buscar novas intervenções rumo a melhoria da qualidade da aprendizagem matemática realizada por meio do ambiente escolar.

Toda e qualquer metodologia de ensino deve ser analisada, refletida e transformada constantemente, para isso é necessário que estejamos acompanhando o desenvolvimento dos alunos, pois um baixo rendimento dos discentes pode sugerir em mudanças na metodologia do professor que possam vir a melhorar suas condições de aprendizagem. Dessa forma, entendemos que as novas tecnologias da informação e comunicação (NTIC) e os jogos poderão ser muito úteis neste sentido para tentar alcançar um melhor rendimento. Segundo Machado (2015, p. 14):

Acreditamos que o uso das NTIC pelo professor em sala de aula abordada de maneira investigativa, poderá produzir conhecimentos em sala de aula e fora dela que servirão de base para que o aluno estabeleça a conexão, teoria e prática na sua aprendizagem, além de imprimir em sua formação um caráter investigativo, reflexivo e problematizador.

Partindo desse pressuposto, destacamos que existem ferramentas que podem identificar com mais clareza os conteúdos exatos onde os alunos tiveram mais dificuldades, trabalhando o conteúdo de forma mais específica e melhorando a qualidade da avaliação.

Neste contexto, utilizaremos o aplicativo plickers, com o intuito de detectar os principais obstáculos epistemológicos na aprendizagem dos estudantes em relação a alguns conteúdos de trigonometria. O aplicativo é um exemplo de NTIC, pois necessita da utilização de um smartphone. Além disso, pode ser classificado como um jogo educacional, pois durante sua aplicação é despertado o sentimento competitivo entre os alunos. Considerando que é possível verificar quem acertou mais questões em tempo real, o método proporciona uma avaliação de forma lúdica, descontraída, porém, com seriedade, quebrando as barreiras que a disciplina de matemática carrega historicamente de ser a mais difícil e o medo de muitos.

Assim o objetivo geral desta pesquisa é identificar como o uso do aplicativo plickers poderia contribuir de forma significativa na melhoria da aprendizagem dos alunos.

Um dos momentos cruciais durante o processo de ensinoaprendizagem é a avaliação, de tal modo que o professor se tornou quase um sinônimo de avaliador, o que traz uma carga muito grande para esse 
profissional na condução desse processo. Além de elaborar estratégias para que sejam verificados os níveis de aprendizagem do aluno em relação a determinado conteúdo, outra etapa importante é verificar onde estão concentrados os obstáculos epistemológicos, e compreendendo a avaliação como um instrumento de aprendizagem, o educador deve retornar para esses pontos com novas estratégias na tentativa de sanar essas dificuldades.

\begin{abstract}
Luckesi (2011) afirma que avaliação se refere à análise qualitativa sobre dados advindos do processo de ensino e aprendizagem, que orienta e auxilia o docente em ações decisórias no transcurso de seu trabalho educativo. O educador deveria, portanto, organizar suas práticas pedagógicas mediante a análise das informações que obtém por meio da avaliação. Entendemos, assim, a avaliação como um feixe de experiências que pode contribuir para subsidiar e indicar rumos à intervenção pedagógica (LUCKESI apud BENTO, NETO, OLIVEIRA, 2017, p. 3).
\end{abstract}

Nesse contexto o aplicativo plickers surge como uma possibilidade de intervenção para auxiliar no diagnóstico dos entraves encontrados pelos alunos. Através da utilização do aplicativo plickers como suporte do processo avaliativo, é possível que se permita ocorrer a interação aluno-aluno, alunoprofessor. Além disso, devido ao seu rápido retorno dos resultados é possível também que o aluno participe na avaliação de suas próprias aprendizagens, refletindo sobre o que acabou de fazer e verificar qual a incoerência na resposta, de forma que possa vir a intervir imediatamente na resolução, configurando assim um processo de avaliação formativa.

\begin{abstract}
A avaliação formativa é aquela que permeia toda ação de formação, fornecendo retorno imediato aos estudantes sobre seu desenvolvimento e quais habilidades precisam ser melhoradas, e aos professores sobre quais rumos tomar no processo ensinoaprendizagem. (DITZZ, GOMES, 2017, p. 3)
\end{abstract}

Percebemos assim, que o aluno participa diretamente do seu processo de construção e evolução de aprendizagem, tornando a mesma mais significativa e transformadora, principalmente ao se tratar de processo de avaliação o qual os alunos tendem a temer.

\title{
1.1 Uso de NTIC na educação
}

A utilização de mídias para o ensino da matemática é capaz de favorecer imensamente o aprendizado, auxiliando o processo pedagógico e proporcionando a investigação científica e experimental. As transformações realizadas perante os grupos sociais apontam para a educação em relação ao ensino de matemática em associação ao uso da tecnologia. As mídias tecnológicas desenvolvem soluções, para os questionamentos dos alunos, através de recursos tecnológicos como calculadoras e aplicativos de internet, softwares, programas computacionais e outros.

Nesse sentido, Borba e Penteado (2001) apresentam exemplos e considerações em relação ao uso de mídias tecnológicas no ensino da matemática, como por exemplo, o uso da calculadora gráfica, vista como um computador portátil com programas que permitem o trabalho da geometria, 
cálculo diferencial, estatística e funções. Quando utilizada como recurso, essas tecnologias se tornam aliadas na construção do conhecimento dos educandos.

Ao longo do surgimento das NTIC, definidas como um conjunto de recursos tecnológicos manipulados para determinado objetivo comum, foram construídas diversas ferramentas que se aliaram à educação para o ensino da matemática, mostrando êxito através da criação de AVA (Ambientes Virtuais de Aprendizagem) onde os educandos trocam informações e experiências; já os educadores, podem elaborar em grupos, fóruns e comunidades para discussão dos mais diversos assuntos e interesses.

Percebe-se a riqueza e a infinidade de possibilidades quando se atrela as mídias tecnológicas à metodologia e didática na práxis pedagógica da sala de aula, diante das atividades realizadas somente com recursos convencionais. $\mathrm{O}$ aplicativo plickers explicado no decorrer desta pesquisa abrange o processo avaliativo com uma maior facilidade e agilidade para alunos e professores.

Atualmente a educação tem passado por momentos de discussões e reflexões no que se refere ao ensino e aprendizagem. A educação hoje já não é mais a mesma de antes em um mundo conectado o tempo todo, a tecnologia já faz parte da educação. Percebemos que esta temática necessita que seja abordada a reflexão, organização e planejamento de ações que permitam que as novas tecnologias implantadas nas escolas, sejam de fato para o fim a que se destinam. No entanto, é comum verificarmos escolas onde não há profissionais com qualificação necessária para extraírem todo o potencial que as NTIC podem oferecer de forma a contribuir para a didática em sala de aula, muitas vezes desconhecem ou desvalorizam as NTIC para educação no ensino e aprendizagem.

Uma das dificuldades mais comuns não se concentra na distribuição dos equipamentos nas escolas, mas nas mudanças de padrões culturais do professor. É necessário a conscientização de que não é mais possível adiar a inserção de recursos tecnológicos na educação. Para que isso aconteça, é primordial informar e planejar estratégias de comunicação destinadas a qualificar e informar as demandas educativas, criando um contexto mais favorável para incorporação, na implementação das NTIC de forma adequada às necessidades educativas. Podemos perceber a importância dessa necessidade conforme afirma Machado (2015, p. 81):

A maioria dos professores de Matemática que trabalham hoje
aprenderam matemática sem o uso de tecnologia. Porém, há uma
necessidade urgente de que os professores dominem as
tecnologias, em particular aplicadas ao ensino, para que possam ter
uma profunda influência no ensino de matemática. Não podemos
continuar atuando no ensino da mesma forma que aprendemos.

Não há mais como fugir da era tecnológica, onde através de um simples celular os alunos possuem os mais diversos recursos de aprendizagem. É necessário que os professores possam se reinventar e compreender que os aparelhos não assumirão o lugar do professor e sim será um instrumento facilitador para melhorar o processo de ensino e consequentemente da aprendizagem. 


\section{METODOLOGIA}

A atividade se trata de um relato de experiência realizado em uma turma do $2^{\circ}$ ano de ensino médio no Instituto Federal do Pará, campus Belém. Participaram da atividade 28 alunos. A fim de se diagnosticar as principais dificuldades dos alunos, foi proposto um teste avaliativo utilizando o aplicativo plickers, através de cinco questões envolvendo o conteúdo de trigonometria para que os estudantes as resolvessem de forma individual em um intervalo de tempo de 100 minutos de aula. As questões foram propostas de forma sucessiva, ou seja, uma de cada vez através de projetor. Os alunos tiveram 15 minutos no máximo para responder cada pergunta por intermédio dos cartões impressos no ambiente web plickers que foram entregues a eles no início da aula.

Ao fim do teste, o professor verificou o relatório e as estatísticas com os percentuais de acerto e já informou as notas individuais de cada aluno, neste momento, alguns estudantes já solicitaram a explicação para as questões respondidas de maneira errônea. Esse tempo final para algumas correções já estava contemplado no planejamento da atividade, portanto houve tempo suficiente para atendimento destes alunos ao término da aula.

\subsection{Planejamento da avaliação através do aplicativo plickers}

O website plickers é um sistema que auxilia na avaliação educacional e que necessita de um smartphone, utilizado pelo professor para fazer a leitura das respostas dos estudantes, que podem ser de múltipla escolha (no máximo quatro alternativas) ou verdadeira e falsa. O professor deverá instalar o aplicativo que está disponível nos sistemas operacionais android e IOS, a sua utilização dispensa o uso de qualquer tipo de dispositivo por parte dos alunos, necessitando que apenas o educador possua o smartphone.

Antes da avaliação em sala de aula as questões devem ser cadastradas com seus respectivos gabaritos no ambiente web, juntamente com a turma e o nome dos alunos que participarão da atividade de avaliação. Cada aluno recebe então, um cartão o qual dependendo da posição poderá representar as letras a, b, c e d em uma questão de múltipla escolha. A cada questão avaliada, o educador visualiza pelo celular em tempo real a quantidade de acertos e erros na turma, de modo que é possível verificar com extrema facilidade o conteúdo que não foi bem assimilado pelos estudantes.

Após a realização da atividade é possível verificar através do ambiente web, o percentual de acertos de cada questão/conteúdo, bem como a nota final de cada aluno, dispensando a necessidade do professor executar qualquer tipo de correção. 
Uma das grandes vantagens do aplicativo consiste no fato deste ser gratuito, com uma interface extremamente amigável, apesar de seu website ser inteiramente na língua inglesa.

Listaremos abaixo as etapas para desenvolvimento de atividade avaliativa de matemática envolvendo o referido aplicativo:

1aㅡ etapa: Criar uma conta com nome de usuário e senha para acesso no website www.plickers.com;

$2^{\text {a }}$ etapa: Após executar o acesso a sua conta, é necessário criar/nomear uma turma clicando em "Add Class" conforme a Figura 1. Exemplo: vamos criar a "Turma do $3^{\circ}$ ano";

Fig. 1. Adicionando uma turma no website plickers

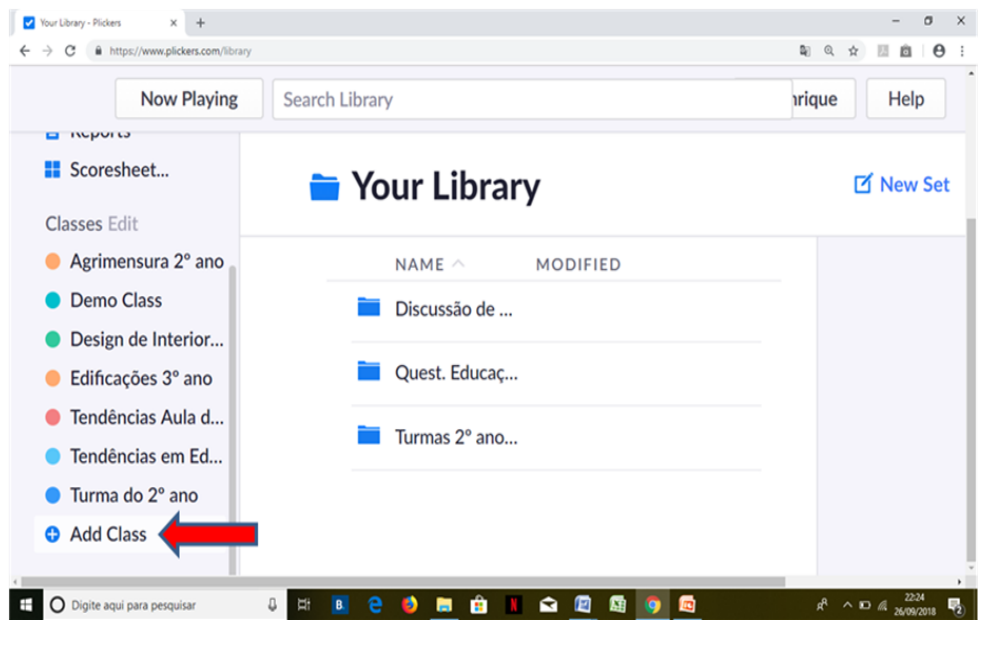

Fonte: Os autores

$3^{\text {a }}$ etapa: Clicar na turma do $3^{\circ}$ ano e depois em "Add Students" (Figuras 2 e 3 respectivamente);

Fig. 2. Clicando na turma para adicionar estudantes

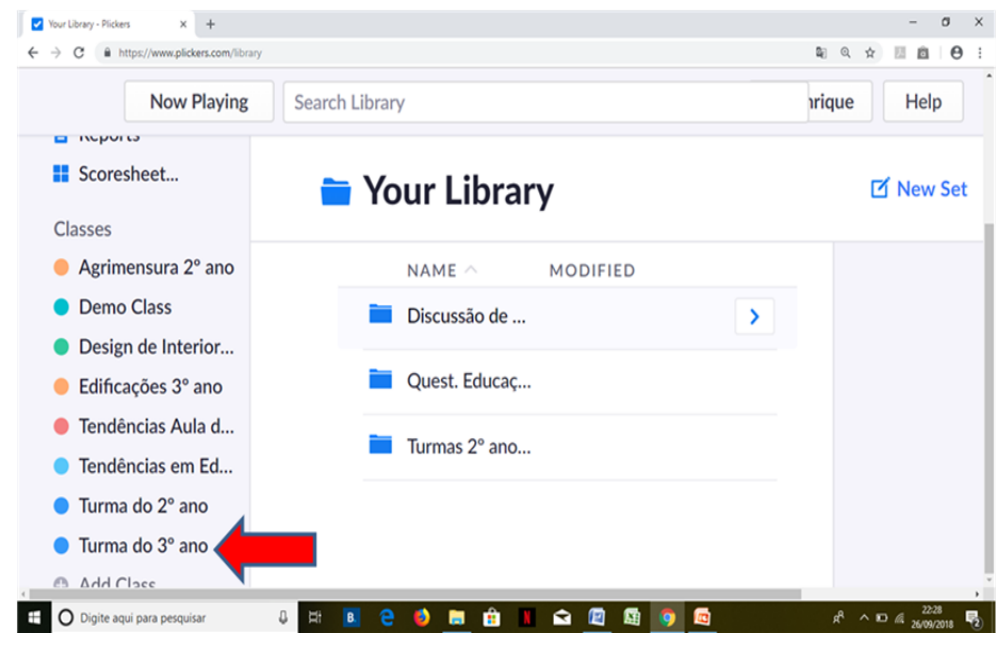

Fonte: Os autores 
Fig. 3. Adicionando estudantes no website plickers

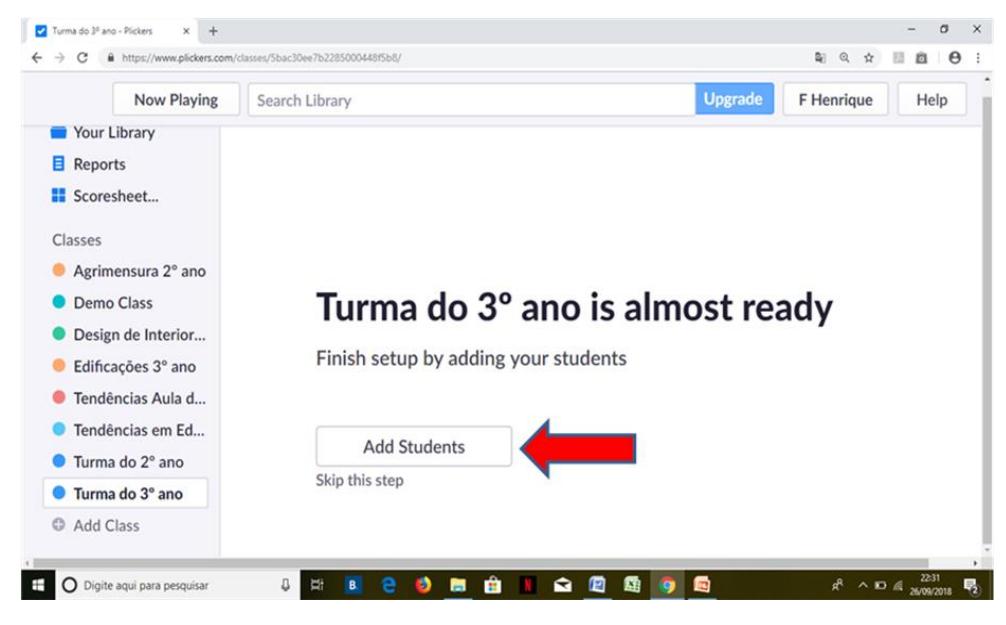

Fonte: Os autores

4⿳亠丷厂 etapa: Inserir o nome e sobrenome dos alunos que participarão da atividade avaliativa de acordo com a Figura 4. Cada linha corresponde a um estudante. Caso a atividade seja em grupo, nesta tela devem-se inserir os nomes dos grupos. Na versão gratuita do aplicativo existe o limite de cadastro para no máximo 63 alunos.

Fig. 4. Nomeando os estudantes no website plickers

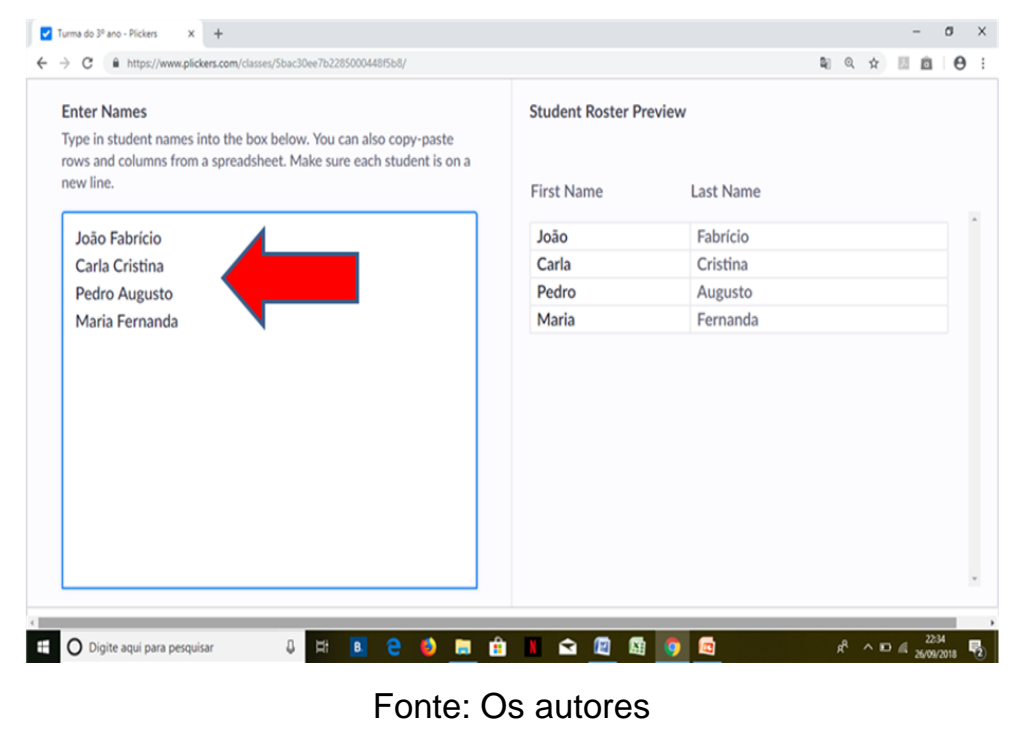

5 etapa: Cada estudante ou grupo ficará vinculado a um cartão. Para imprimir os cartões, deve-se clicar em Help e depois Get Plickers Cards (Figura 5); 
Fig. 5. Acessando os cartões para impressão

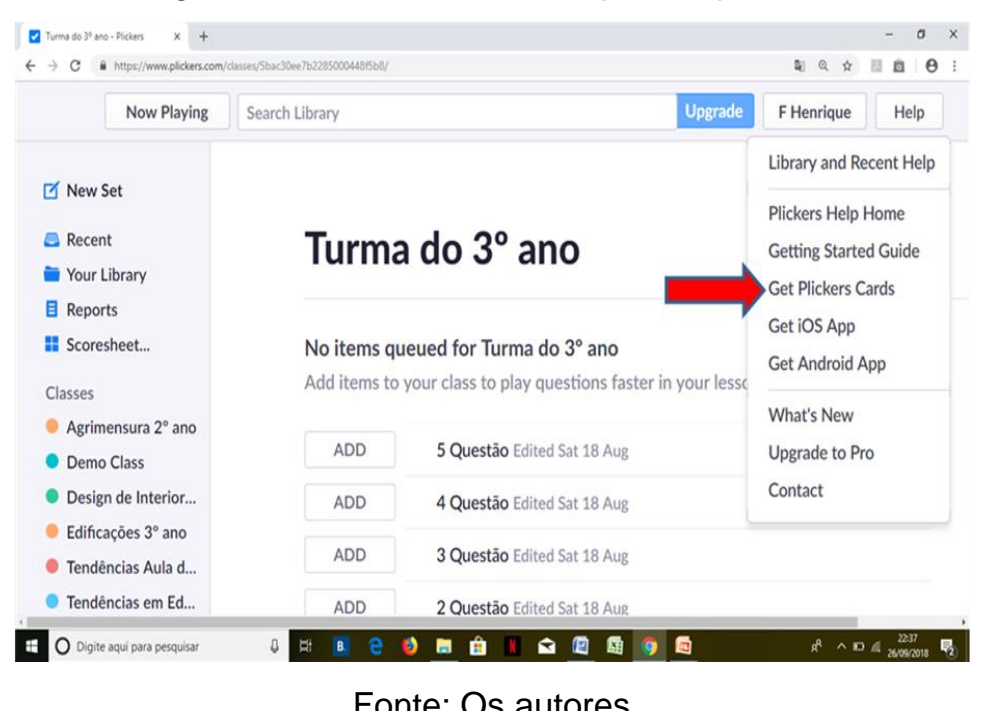

Fonte: Os autores

6 a etapa: Clicar em Expanded para imprimir o máximo de 63 cartões (Figura $6)$;

Fig. 6. Imprimindo os cartões

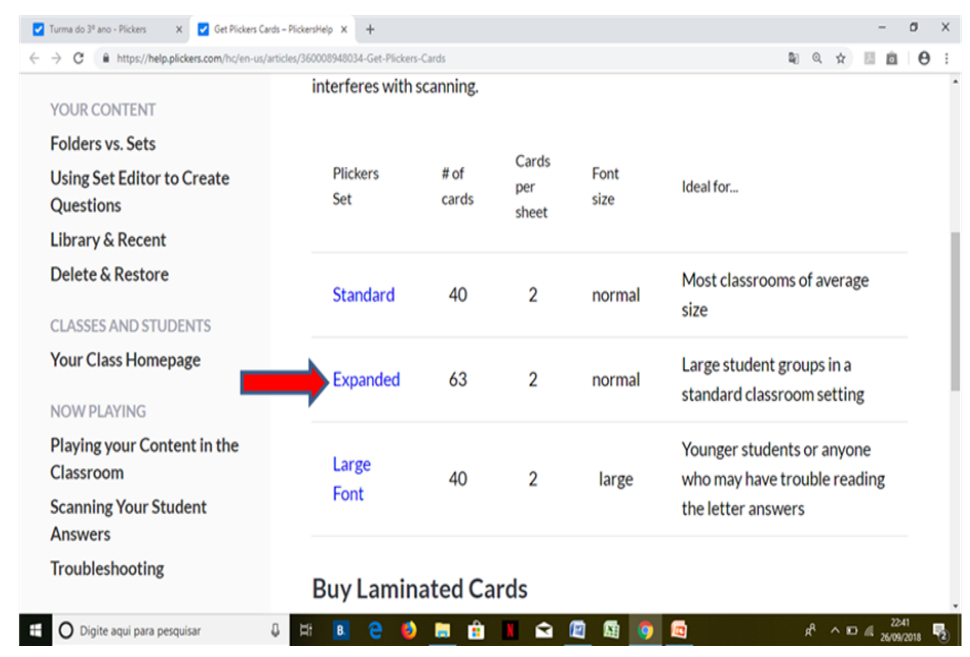

Fonte: Os autores

7a etapa: entregar o cartão (Figura 7) correspondente a cada aluno no dia da atividade avaliativa de acordo com o cadastro no ambiente web. A cada questão proposta pelo professor em sala de aula através de um projetor, o aluno deverá mostrar seu cartão com a sua resposta $(a, b, c$ ou d, dependendo do posicionamento do cartão) para que o professor faça a leitura pelo aplicativo plickers. 
Fig. 7. Exemplo de cartão entregue aos alunos

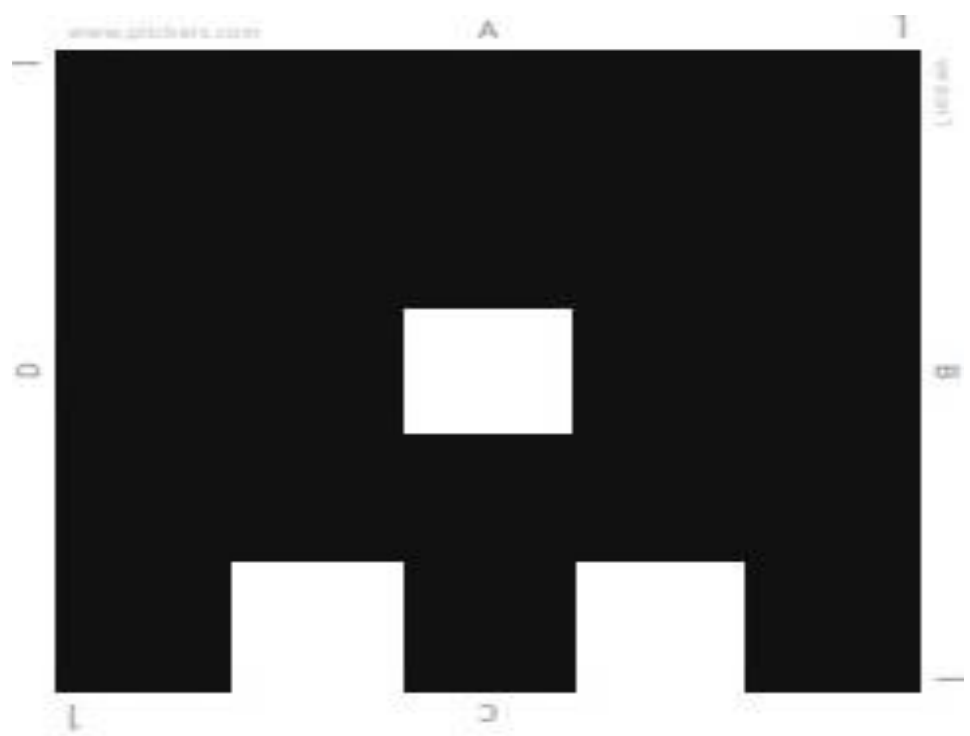

Fonte: Os autores

\section{RESULTADOS E DISCUSSÕES}

Após o teste avaliativo, necessitamos acessar o ambiente web plickers, onde podemos extrair diversos relatórios evidenciando tanto os desempenhos individuais dos alunos, quanto o desempenho global da turma. Na Figura 8, ressaltamos o percentual de acertos da classe em cada questão:

Fig. 8. Percentual de acertos por questão

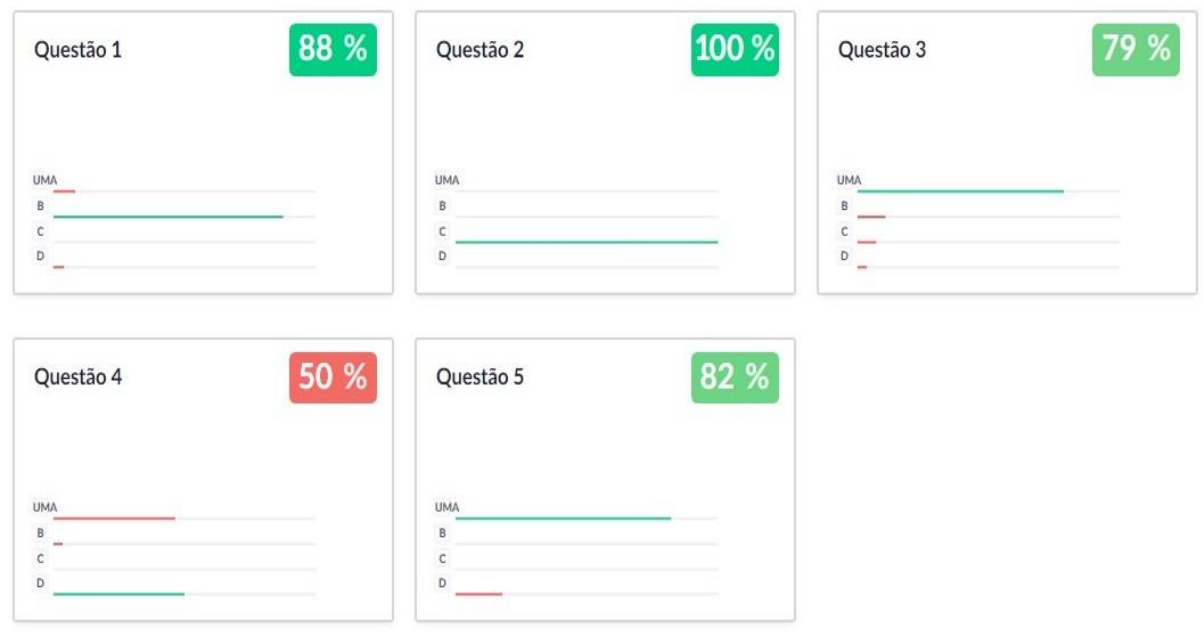

Fonte: Os autores 
É possível constatar pelo relatório da Figura 8 que metade da turma $(50 \%)$ errou a questão № 4 (Figura 9). Considerando um percentual de acertos acima de $70 \%$ como satisfatório, verificou-se que o desempenho dos alunos quanto a esta questão foi insatisfatório.

Desta forma, o professor identificou a necessidade de executar uma revisão quanto ao conteúdo da quarta questão a fim de esclarecer o assunto relativo à principal dificuldade dos alunos.

Fig. 9. Questão 4

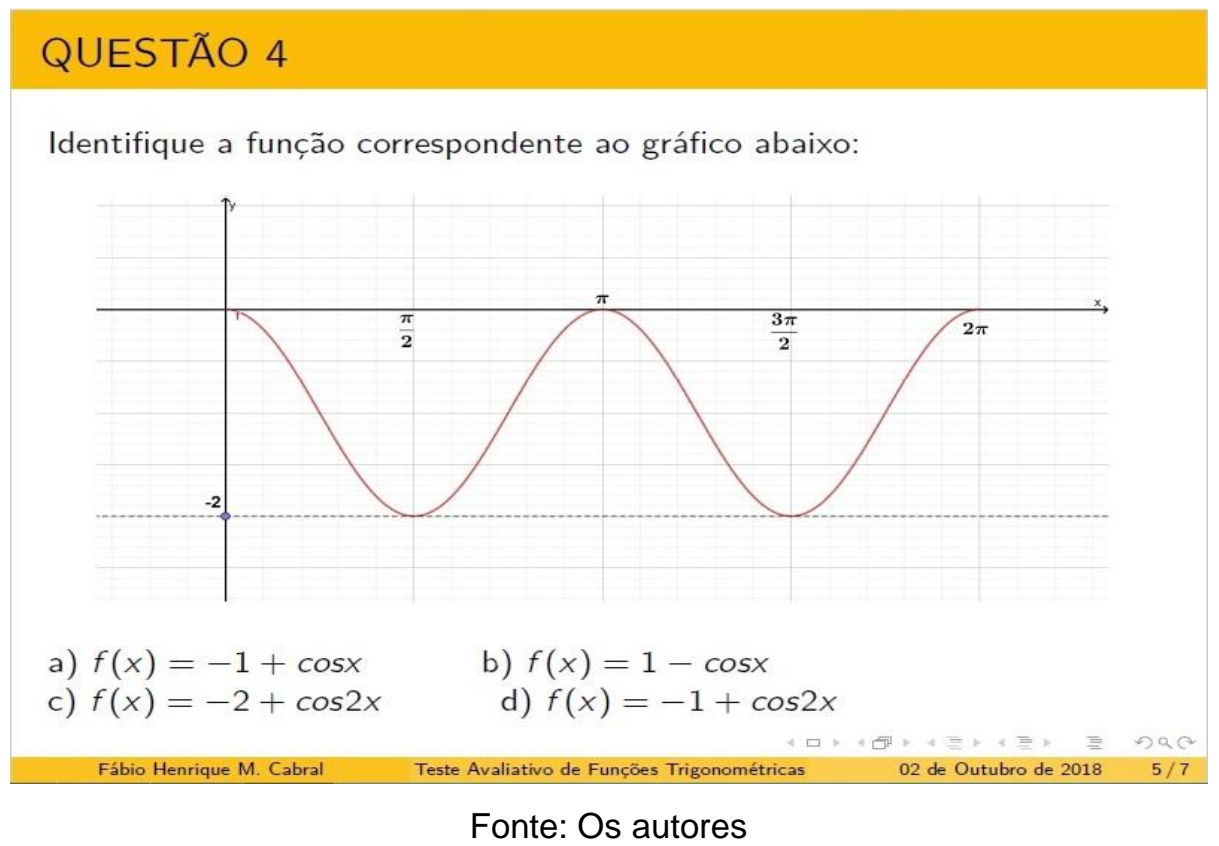

Foi possível concluir também através dos relatórios no ambiente web que seis alunos obtiveram nota inferior a $70 \%$, conforme pode-se observar na Figura 10. O docente poderá então acompanhar o desempenho destes durante as atividades em sala de aula de forma a tentar melhorar seus rendimentos até a prova final. Na figura abaixo, ocultamos os nomes dos alunos de forma a se preservar a identidade dos mesmos.

Fig. 10. Relatório do desempenho individual dos alunos 


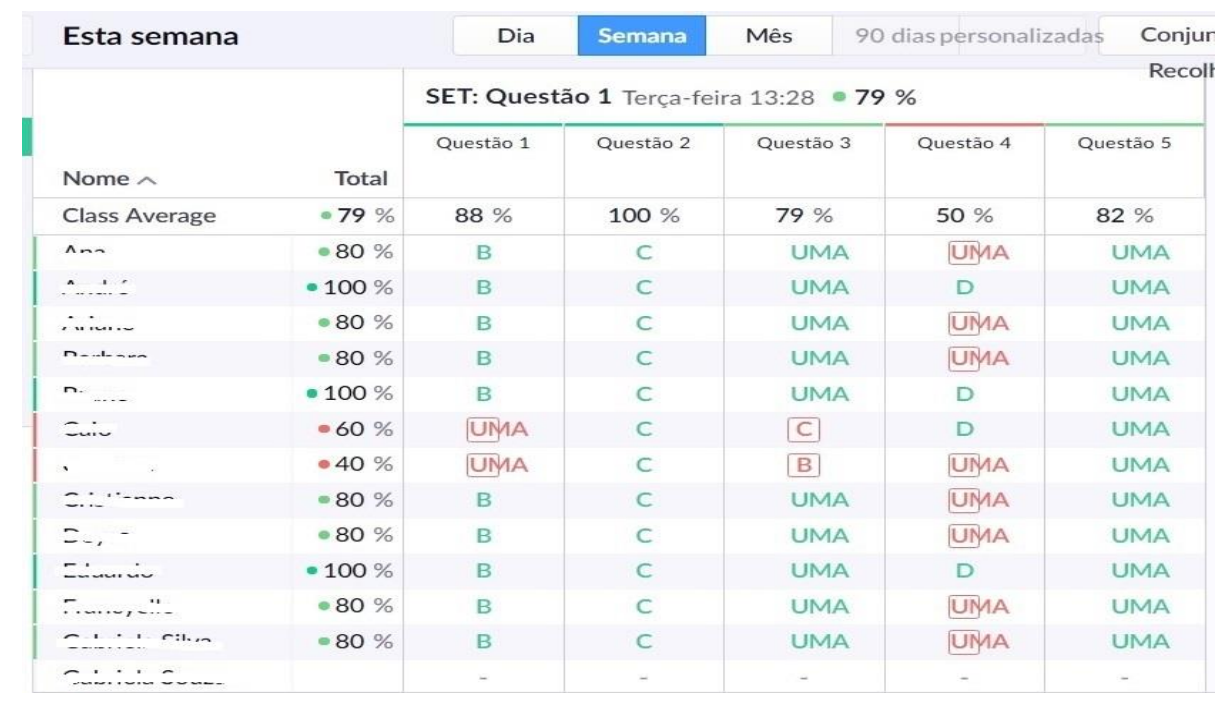

Fonte: Os autores

Ao final da atividade avaliativa foi distribuído aos alunos um questionário semiestruturado com três perguntas abertas e três fechadas com a finalidade de compreender de que maneira a utilização do aplicativo contribui na melhoria do processo de ensino aprendizagem segundo a percepção destes.

No item 1, aproximadamente $96 \%$ dos alunos afirmaram que já tiveram alguma situação de bloqueio durante um teste avaliativo.

No item 2, cerca de $93 \%$ disseram que o referido bloqueio já ocorreu durante um teste de matemática.

No item 3, os alunos listaram alguns motivos que levam a este esquecimento durante as provas: nervosismo, pressão por ter que alcançar a média 7.0, ansiedade, medo e insegurança foram os mais citados.

Em relação ao item 4, um percentual de $86 \%$ dos estudantes responderam que o uso do aplicativo plickers diminuiu a possibilidade de ocorrer o bloqueio. Reforçando o que afirma Borin (1996, p. 53),

Outro motivo para a introdução de jogos nas aulas de matemática é a possibilidade de diminuir bloqueios apresentados por muitos de nossos estudantes que temem a matemática e sentem-se incapacitados para aprendê-la. Dentro da situação de jogo, onde é impossível uma atitude passiva e a motivação é grande, notamos que, ao mesmo tempo em que estes alunos falam Matemática, apresentam também um melhor desempenho e atitudes mais positivas frente a seus processos de aprendizagem.

Já no item 5, os alunos declararam que o aplicativo difere de uma prova tradicional devido a: dinâmica diferente, menor "peso", "quebra" um pouco da pressão, teste mais extrovertido descontrai mais e faz com que os alunos lembrem o que foi visto em sala e a prova tradicional deixa a pessoa nervosa, é mais descontraído, mais tranquilidade. Apenas um aluno afirmou que não difere em nada.

No item 6, foi listado pelos alunos os aspectos positivos e negativos do plickers. Os aspectos positivos são: melhora o aprendizado, agilidade da correção, ajudar a ficar mais calmo durante a avaliação, mais prático, maior 
interação entre professor e aluno, melhor concentração, menor "pressão" comparada à prova comum, é uma forma descontraída de estudar.

Quanto aos aspectos negativos obtivemos as seguintes respostas: tempo limitado para resolução das questões, não pode ser levado tão a sério quanto um teste tradicional, impossibilita o uso de questões subjetivas, corre o risco de o sistema falhar e fazer leitura incorreta da questão.

\section{CONSIDERAÇÕES FINAIS}

Após a análise dos resultados, avaliamos o aplicativo como um ótimo instrumento visando à melhoria do ensino e da aprendizagem. Não temos a pretensão de apontar esta tecnologia como a principal fonte de avaliação do educador, mas sim como uma ferramenta de auxílio para diagnosticar as principais dificuldades dos estudantes em relação aos conteúdos ministrados em sala de aula. Destacamos ainda outros pontos positivos como a diminuição da tensão de uma prova tradicional, aplicação da avaliação de forma lúdica, facilidade de correção do professor com conseqüente otimização de tempo e aumento da motivação dos estudantes.

\section{REFERÊNCIAS}

BENTO, M. C. M.; NETO, J. A. M.; OLIVEIRA, N. A. A.; Metodologias ativas e novas tecnologias: o uso do plickers como ferramenta de avaliação.

Disponível em:< http://www.abed.org.br/congresso2017/trabalhos/pdf/33.pdf>. Acesso em 04 Out 2018.

BORBA. M. C.; PENTEADO. M. G. Informática e educação matemática. 1. ed. Belo Horizonte: Autêntica, 2001.

BORIN, J. Jogos e resolução de problemas: uma estratégia para as aulas de matemática. 6 ed. São Paulo: IME - USP, 1996.

DITZZ, A. J. M.; GOMES, G. R. R. A utilização do aplicativo plickers no apoio a avaliação formativa. Revista Tecnologias na Educação- Ano 9Número/Vol.19- Julho 2017.

MACHADO, B. F. Aulas de matemática com o auxílio de tecnologias digitais. Belém: SBEM - PA, 2015. 